\title{
Recent advances on the progressive mechanism and therapy in castration-resistant prostate cancer
}

This article was published in the following Dove Press journal:

OncoTargets and Therapy

\author{
Keshan Wang' \\ Hailong Ruan' \\ Tianbo $\mathrm{Xu}^{\prime}$ \\ Lei Liu' \\ Di Liu' \\ Hongmei Yang ${ }^{2}$ \\ Xiaoping Zhang' \\ Ke Chen' \\ 'Department of Urology, Union \\ Hospital, Tongji Medical College, \\ Huazhong University of Science and \\ Technology, Wuhan 430022, China; \\ ${ }^{2}$ Department of Pathogenic Biology, \\ School of Basic Medicine, Huazhong \\ University of Science and Technology, \\ Wuhan 430030, China
}

Correspondence: Xiaoping Zhang;

Ke Chen

Department of Urology, Union Hospital, Tongji Medical College, Huazhong University of Science and Technology (HUST), I 277 Jiefang Avenue, Wuhan 430022, Hubei Province, China

Tel +86278535 I625

Email xzhang@hust.edu.cn;

shenke@hust.edu.cn
Background: Although there have been great advances in mechanisms and therapeutic methods of prostate cancer, the mortality rate of prostate cancer remains high. The castration-resistant prostate cancer (CRPC), which develops from hormone-sensitive prostate cancer, foreshadows a more dismal outcome. Concomitant with the researches in the mechanism of CRPC and therapy for CRPC, more and more landmark progress has been made in recent years.

Methods: A number of clinical and experimental studies were reviewed to indicate the novel advancement in the progressive mechanism and therapy of CRPC.

Results: The androgen receptor $(A R)$ is still a vital driver in the progression of CRPC, while other multiple mechanisms also contribute to this progression, such as tumor immunity, cancer stem cells, epithelial-mesenchymal transition and DNA repair disorder. In terms of the therapeutic methods of CRPC, chemotherapy with drugs, such as docetaxel, has been the first-line therapy for CRPC for many years. Besides, newer agents, which target some of the above mechanisms, show additional overall survival benefits for CRPC patients. These therapies include drugs targeting the androgen axis pathway (androgen synthesis, androgen receptor splice variants, coactivators of AR and so on), PI3K-AKT pathway, WNT pathway, DNA repair, rearrangement of ETS gene, novel chemotherapy and immunotherapy, bone metastasis therapy and so on. Understanding these novel findings on the mechanisms of CRPC and the latest potential CRPC therapies will direct us for further exploration of CRPC.

Conclusion: Through comprehensive consideration, the predominant mechanism of CRPC might be the AR signal axis concomitant with tumor microenvironment, stress, immunity, tumor microenvironment and so on. For CRPC therapy, targeting the AR axis pathway and chemotherapy are the first-line treatments at present. However, with the advancements in CRPC therapy made by the researchers, other novel potential methods will occupy more and more important position in the treatment of CRPC, especially the therapies targeting the tumor microenviroment, tumor immunity and DNA repair and so on.

Keywords: CRPC, androgen receptor, tumor immunity, mechanism, therapy

\section{Introduction}

Prostate cancer, which has the highest incidence among male malignancies in European and American countries, seriously threatens human health and affects the patients' life quality. ${ }^{1}$ According to the statistics, the incidence and mortality rates of prostate cancer have been increasing every year with the rapid increase in Chinese aging society. Specifically, the castration-resistant prostate cancer (CRPC), which develops from hormone-sensitive prostate cancer, has a much higher mortality rate compared with prostate cancer. ${ }^{2}$

The clinical prognosis of CRPC patients is still unsatisfactory despite the fact that several important mechanisms and therapy advancements of CRPC have been reported. 
New drugs such as docetaxel, abiraterone and enzalutamide that could delay, to a certain extent, the development of CRPC are still the main therapy agents for CRPC in clinical practice. ${ }^{3}$ In recent years, numerous progressive mechanisms and therapeutic targets of CRPC have been found due to the efforts of the researchers. In this paper, we will review the novel research advancements of the progressive mechanisms and therapy in CRPC.

\section{The progressive mechanisms of CRPC}

At present, gene alteration in the androgen axis and the kinase-dependent signal pathways are the most important mechanisms of CRPC genesis and development. However, accumulated evidences have indicated that tumor immunity, cancer stem cells (CSCs), epithelial-mesenchymal transition (EMT), DNA repairing disorder and other mechanisms might also participate in the progress of CRPC (Figure 1).

\section{De novo synthesis of androgen}

The levels of intratumoral androgen in some CRPC patients were higher than in the primary prostate cancer patients, although serum testosterone $(\mathrm{T})$ was at the castration level $(<1.7 \mathrm{nmol} / \mathrm{L})$ in these CRPC patients. ${ }^{4}$ According to the recent research, the mechanisms of de novo synthesis of androgen are discussed next.

\section{Cytochrome P450 family-induced synthesis}

The synthesis of $\mathrm{T}$ and dihydrotestosterone depends on the cytochrome P450 (CYP) family. CYP17, a member of the CYP family, has been proved to play a vital role in CRPC.
Abiraterone acetate, one of the most common medicines for CRPC, is a kind of inhibitor of CYP17 and has been proved to improve the prognosis of CRPC patients. $^{5}$

\section{The synthesis of intratumoral androgen}

According to previous researches, the levels of $\mathrm{T}$ and dihydrotestosterone are mainly dependent on the synthesis of intratumoral androgen, which is based on the conversion of dehydroepiandrosterone in the prostate cancer tissues after androgen deprivation therapy (ADT). This kind of intratumoral androgen synthesis mostly relies on some steroidogenic enzymes such as hydroxysteroid dehydrogenase (HSD) $17 \beta$, HSD3 $\beta$ and steroid-5 $\alpha$-reductase. ${ }^{6}$

The activities of steroidogenic enzymes are also correlated with the expression of some other cytokines. Transforming growth factor beta could regulate the synthesis of the intratumoral androgen by upregulating HSD3 $\beta$ and downregulating HSD17 $\beta$; insulin-like growth factor (IGF)- $\beta$ could promote the synthesis of intratumoral androgen by increasing the expression of CYP17, AKR1C3 and HSD17 $\beta$, so as to improve the development of CRPC. ${ }^{7}$ Moreover, activin A, interleukin (IL)-6 and IGF2 could also regulate the activities of the steroidogenic enzymes. ${ }^{8-10}$

Recently, it was indicated that arachidonic acid could induce the synthesis of StAR, which is bound to hormonesensitive lipase and transforms the free cholesterol into androgen in the steroid synthesis-related cells. ${ }^{11}$

\section{Elevation of the expression level of androgen metabolism-related genes}

The upregulation of the expression level of the androgen metabolism-related genes, such as $H S D 3 \beta 2, A K R 1 C 3$,

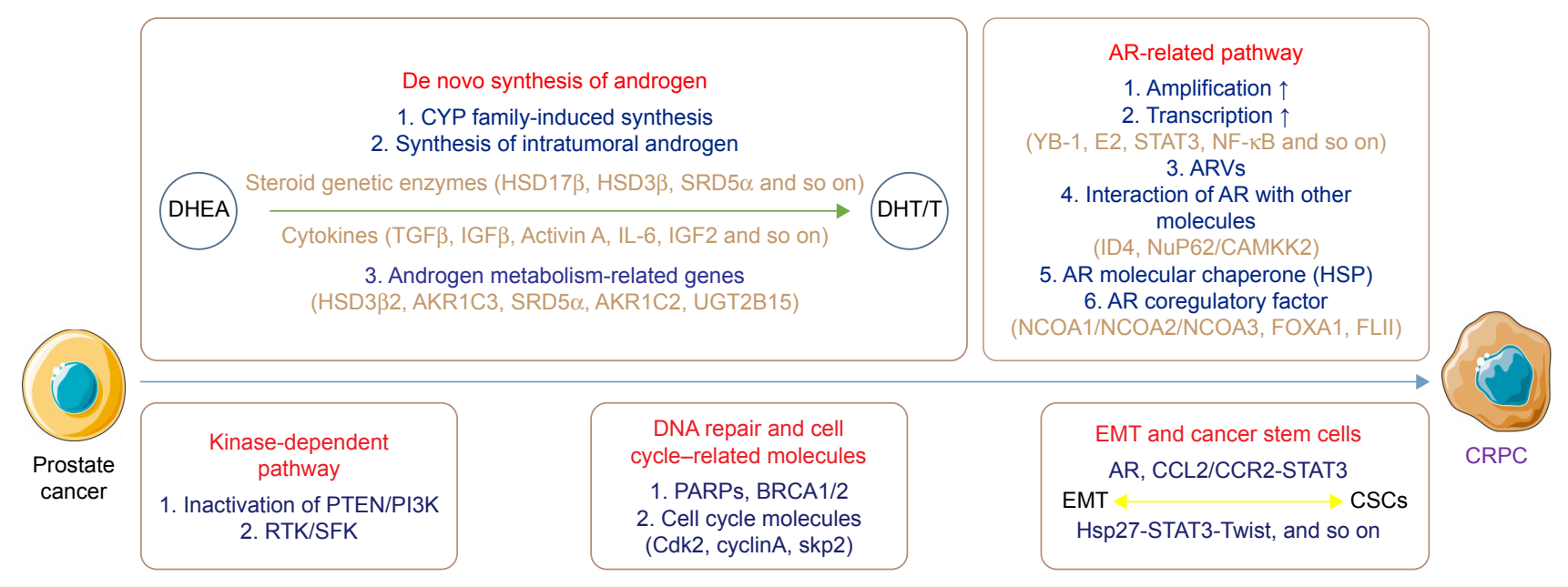

Figure I Main progressive mechanisms of CRPC.

Abbreviations: AR, androgen receptor; ARVs, AR splice variants; CRPC, castration-resistant prostate cancer; CSCs, cancer stem cells; CYP, cytochrome P450; DHEA, dehydroepiandrosterone; DHT, dihydrotestosterone; EMT, epithelial-mesenchymal transition; HSP, heat shock protein; T, testosterone; HSP, heat shock protein. 
$S R D 5 \alpha, A K R 1 C 2$ and $U G T 2 B 15$, also plays an important role in the development of CRPC. ${ }^{12}$

\section{The regulatory effect of tumor microenvironment in CRPC}

Recent studies have demonstrated that the synthesis of intratumoral androgen is related to the tumor microenvironment to a certain extent. The expression levels of steroidogenesis enzymes in the stromal cells are much higher in the CRPC cells. Meanwhile, the activity of prostate specific antigen (PSA) promoter, which is induced by dehydroepiandrosterone through androgen receptor (AR) activation in CRPC cells, could also be enhanced by prostate stromal cells. ${ }^{13}$ Besides, the anti-angiogenesis effect induced by vascular endothelial growth factor also plays a vital role in the progress of CRPC, while the vascular endothelial growth factor-targeted therapy was suggested to be useful for CRPC according to a study. ${ }^{14}$

\section{The adaptive variation of AR-related pathway}

During the progress of CRPC, the adaptive variation of ARrelated pathway plays a vital role and the variation mainly focuses on the following parts.

\section{The amplification of AR gene}

The depletion of AR ligands could lead to the amplification of AR gene via feedback regulation. ${ }^{15}$ The overexpression and the importance of AR signaling in androgen-independent prostate cancer have been proved by reports. ${ }^{16,17}$ The amplification of AR gene could directly increase the expression level of AR and accelerate the development of CRPC. According to studies, glucocorticoid receptor could regulate some of AR targets in CRPC cells, and endostatin could inhibit glucocorticoid receptor-induced resistance upon AR antagonism. ${ }^{18,19}$

\section{The transcription activity of AR gene}

The regulation of AR transcription via cytokine plays an important role in the development of CRPC. YB-1 protein could combine with the Y-box domain in AR promoter and regulate the transcription of AR gene. ${ }^{20}$ The estrogen E2 could enhance the expression of SOX4, which is a member of the AR transcription factors in CRPC cells. ${ }^{21}$ Besides, STAT3, NF- $\kappa B$ and NF- $\kappa B / p 52$ could also activate the transcription of $A R$ and increase its expression level through different pathways. ${ }^{22-24}$

\section{The mutation of AR gene}

The mutation of ligand-binding domain (LBD) or coeffective areas in AR gene could decrease the specificity of the combination between AR and its ligands, while the mutation of $\mathrm{F} 876 \mathrm{~L}$ region in $\mathrm{AR}$ gene has been demonstrated to be correlated with enzalutamide resistance in CRPC. ${ }^{25}$ Furthermore, the generation of AR splice variants (ARVs) is reported to play an important role in the development of CRPC, especially the AR-V7, which is transferred from AR due to a deficiency of LBD ligand. The expression of AR-V7 could activate the androgen synthesis-related genes and promote the progression of CRPC. ${ }^{26}$

\section{The interactions between AR and other molecules} Besides the above signal pathways, the activity of AR is also correlated with some other molecules. The inactivation of inhibitor of differentiation 4 could activate the $\mathrm{AR}$ and promote CRPC. ${ }^{27}$ Nucleoporin62 and calcium/calmodulindependent protein kinase kinase 2 could impact the activity and development of CRPC. ${ }^{28}$

\section{The regulator effect of AR molecular chaperone}

As a molecular chaperone of AR, the expression of heat shock proteins (HSPs), especially HSP27 and HSP90, could be induced by ADT. It was reported that the activation of HSP27 and HSP90 might contribute to the resistance of ADT. ${ }^{29}$

\section{The modulation of AR co-regulatory factor}

The implementation of AR function was also associated with some co-regulatory factors. The nuclear receptor coactivators (NCOAs)1, NCOA2 and NCOA3, which are the members of non-receptor tyrosine kinase (SRC) family and coactivators of AR, have attracted special attention of the researchers. ${ }^{30}$ Meanwhile, forkhead box A1 (FOXA1), another cofactor, could modulate the transcription of $\mathrm{AR}$ and regulate the development of CRPC via GAT 3A2 gene. ${ }^{31}$

A recent study demonstrated that the Flightless I Homolog, FLII, could activate as a kind of transcriptional co-regulatory factor of AR and suppress the development of CRPC by regulating the cellular localization of AR in prostate cancer cells and inhibiting the expression of AR. This study revealed that FLII might be an important therapy target of CRPC. ${ }^{32}$

\section{The regulator effect of kinase-dependent pathway}

The kinase-dependent signal pathway, which is modulated by AR axis during ADT, also plays a vital role in the development of CRPC. The inactivation of PTEN gene in CRPC patients could activate PI3K resulting in AR activation. ${ }^{33}$ 
In recent years, it was reported that the receptor tyrosine kinases and SRC family kinases could regulate the AR signal and the development of CRPC by inducing the phosphorylation of AR and inhibiting the expressions of co-regulatory factors of AR. ${ }^{34}$

\section{Modulation of DNA repair genes and cell cycle-related molecules}

Mutation of DNA repair genes might play a vital role in CRPC. ${ }^{35}$ Poly (ADP-ribose) polymerase, which is a kind of DNA repair enzyme, could maintain the function of AR. ${ }^{36}$ Meanwhile, the mutation of BRCA1/2 gene, which is a member of DNA repair gene, was closely correlated with the development of CRPC. ${ }^{37}$ Furthermore, the androgen could inhibit the proliferation of AR-positive CRPC cells through the suppression of Cdk2, CyclinA and Skp2, which are typical members of cell cycle-related cytokines. ${ }^{38}$

\section{The regulation of EMT and CSCs}

In recent years, the importance of EMT and CSCs in the progressive CRPC has been demonstrated by various studies. The expression levels of E-cadherin, N-cadherin, Snail, Twist and other EMT markers are altered significantly during ADT. According to previous studies, ADT could trigger the appearance of EMT, which could further accelerate the development of CRPC.

CSC, a kind of potential malignant epithelial stem cell, might effect as an important regulatory target in CRPC. Some representative markers such as $\mathrm{Nkx} 3.1, \mathrm{CD} 166, \mathrm{PSA}^{-/ \mathrm{LO}}$, Nanog, Bmi-1 and SOX2 are shown to be correlated with the progress of CRPC on the grounds of recent studies. ${ }^{39,40}$

Furthermore, according to a recent study, the interaction between EMT and CSCs might also play a vital role in the recurrence and drug resistance of CRPC through AR, CCL2/CCR2-STAT3, Hsp27-STAT3-Twist and other pathways. ${ }^{41,42}$

\section{The regulation of inflammation cytokines}

The roles of inflammation factors in prostate cancer were proved by accumulating evidences during recent years (Table 1). IL-6 could induce the drug resistance of prostate cancer by activating SRC-1, regulating the expression of genes GRB2, SHC and JAK-1 and inhibiting the apoptosis of CRPC cells. ${ }^{43}$ IL-4, another important inflammation factor, could affect the coactivators of AR, such as CBP/P300 and NF- $\kappa \mathrm{B}$, and regulate the development of CRPC. ${ }^{44} \mathrm{IL}-8$, which could interact with $\mathrm{NF}-\kappa \mathrm{B}$, is overexpressed in CRPC and could promote the angiogenesis and metastasis of CRPC through the SRC and FAK pathway. ${ }^{45}$ Furthermore, CXCR4, CXCR2/CXCR3, CXCR6 and CXCR7, which belong to the CXCR family, also play an important role in the development of CRPC via inflammation pathways according to recent studies. ${ }^{46-50}$ The roles of inflammation factors in cancers have been a hot issue in recent years, and a deeper and broader discussion is expected in future.

\section{The regulation of ncRNAs in CRPC}

The ncRNAs serve as a transcription regulator in CRPC (Table 2). It was known that miRNA could modulate the development of CRPC by regulating the cell cycle, cell differentiation and cell proliferation. ${ }^{51}$ Among the miRNAs, miR-1 and miR-206 could regulate the expression levels of glucose metabolism-related genes such as G6PD, TKT, PGD and GPD2 to affect the development of CRPC. Meanwhile, miR-185, miR-342, miR-17/92 and miR101 could regulate the development of CRPC through influencing SREBP, PPARA, COX-2 and other lipid metabolism-related pathways. ${ }^{52,53}$ Besides, miR-32, miR-148a, miR-99a, miR-2 and miR-221 also play an important role in CRPC via AR signals. ${ }^{54}$

According to studies, lncRNAs such as PRNCR1, PCGEM1 and CTBP-AS could promote the development of prostate cancer by activating and promoting the transcription of AR. ${ }^{55} \operatorname{lncRNA}-\mathrm{p} 21$ could promote the survival of prostate cancer cells through the Warburg effect and hypoxia-inducible

Table I The regulation of inflammation factors in CRPC

\begin{tabular}{llll}
\hline Cytokines & Signaling pathways & Target genes & Possible effect on cancer cells \\
\hline IL-6 & Coactivator of AR & SRC-I/GRB2, SHC, JAK-I & Inhibits apoptosis of the CRPC cells \\
IL-4 & Coactivator of AR & CBP/P300, NF-KB & Induces AR activation \\
IL-8 & Kinase-dependent pathway & NF-KB, SRC, FAK & Promotes angiogenesis and metastasis of CRPC \\
CXCR4 & IL-8 receptor & CXCLI 2/SDF-I & Promotes proliferation, differentiation and \\
CXCR2/CXCR3 & $/$ & I & metastasis \\
CXCLI6/CXCR6 & Akt pathway & IL-8, VEGF & Promotes proliferation and angiogenesis \\
CXCR7 & Akt pathway & IL-8/VEGF, EGFR & Promotes selective metastasis to bone \\
\hline
\end{tabular}

Note: "”" indicates unknown.

Abbreviations: AR, androgen receptor; CRPC, castration-resistant prostate cancer; IL, interleukin. 
Table 2 The regulation of ncRNA in CRPC

\begin{tabular}{|c|c|c|c|c|}
\hline ncRNA & Names & Target gene & Possible effect on cancer cells & References \\
\hline \multirow[t]{3}{*}{ miRNA } & miR-I and miR-206 & G6PD, TKT, PGD and GPD2 & Regulates glucose metabolism & 48 \\
\hline & miR-185, miR-342, miR-I7/92 and miR I0I & SREBP, PPARA and COX-2 & Regulates lipid metabolism & 49 \\
\hline & miR-32, miR-I48a, miR-99a, miR-2 and miR-22I & $A R$ & Activates AR signals & 50 \\
\hline \multirow[t]{4}{*}{ IncRNA } & PRNCRI, PCGEMI and CTBP-AS & $A R$ & $\begin{array}{l}\text { Activates } A R \text { and promotes the } \\
\text { transcription of } A R\end{array}$ & 51 \\
\hline & IncRNA-p2I & Warburg effect-related genes & $\begin{array}{l}\text { Regulates the Warburg effect and } \\
\text { HIF pathway }\end{array}$ & 52 \\
\hline & HOTAIR & $A R$ & $\begin{array}{l}\text { Promotes the proliferation, } \\
\text { invasion and metastasis of CRPC }\end{array}$ & 53 \\
\hline & PCATI and ANRIL & PRC/AR & Modulates the expression of AR & 54,55 \\
\hline
\end{tabular}

Abbreviations: AR, androgen receptor; CRPC, castration-resistant prostate cancer; HIF, hypoxia-inducible factor; PRC, PGC-I-related coactivator.

factor pathway. ${ }^{56}$ In addition, HOTAIR, which is a member of lncRNA, could promote the proliferation, invasion and metastasis of CRPC via the modulation of epigenetics and transcription of AR. ${ }^{57}$ Similarly, the lncRNAs PCAT1 and ANRIL could modulate the expression of AR through interacting with the PGC-1-related coactivator family. ${ }^{58,59}$

\section{The transformation of prostate cancer into neuroendocrine prostate cancer}

Neuroendocrine prostate cancer (NEPC) is insensitive to the ADT. According to recent studies, the loss of RB1 and TP53 and the increase in MYCN and AURKA might be the reasons for the formation of NEPC. ${ }^{60}$ As a result, these genes related with the formation of NEPC are considered as a potential therapy target of NEPC.

\section{The new advancement of CRPC therapy}

Drugs targeting the androgen axis, cytotoxic drugs, immune drugs and drugs targeting bone metastasis (zoledronic acid, ${ }^{233} \mathrm{Ra}$ and denosumab) are the main choices for clinical doctors for CRPC therapy. ${ }^{61,62}$ Moreover, the drugs targeting PI3K-AKT, WNT, DNA repair and other molecular signaling pathways were demonstrated to be essential in CRPC therapy, while the advances in prostate cancer immunity researches also indicated that immunotherapy might be indispensable in CRPC therapy in the future ${ }^{63,64}$ (Table 3).

\section{Targeting the androgen axis pathway}

As a nuclear receptor related to steroidogenesis, AR is constituted by DNA-binding domain (DBD), LBD, N-terminal domain (NTD) and hinge region. The alteration in any component of AR structure might change the activity of $\mathrm{AR}$ and influence the development of CRPC. ${ }^{65}$ As a result, targeting the structural domain of AR is also a hotspot in CRPC.
Inhibition of androgen synthesis

The inhibitors of the key enzymes in androgen synthesis were indicated to have a satisfactory effect in clinical trials. The therapeutic effect of the combination of abiraterone acetate and prednisone for CRPC has been proved in clinical practice. ${ }^{66,67}$ Besides, VT-464, acting on CYP17, could suppress the proliferation of tumor and decrease the PSA level through inhibition of AR-axis. ${ }^{68}$ However, according to a clinical trial, TAK-700 (Orteronel), which also acts on CYP17, showed no significant effect on the overall survival time of CRPC patients. ${ }^{69}$

Although many new drugs might be effective for CRPC, administration of drugs that act upon the AR axis would still be the most essential and important method in CRPC clinical therapy for some time.

\section{Targeting HSP protein}

HSP protein is a very important target in CRPC therapy as mentioned before. ${ }^{29}$ The application of inhibitors targeting the HSP90 protein has been considered as a novel therapeutic strategy for CRPC patients with mutant AR. ${ }^{70}$ Knockdown of TCTP that interacts with HSP27 could suppress the survival and proliferation of CRPC cells. ${ }^{71}$ In recent years, some preclinical studies have indicated that silencing HSP27 or HSP90 could sensitize the prostate cancer cells to chemotherapy and radiation treatments, and several HSP protein inhibitors (tanespimycin, ganetespib, OGX-427) could delay castration resistance or prolong survival in CRPC..$^{72-75}$ Thus, the combination of HSP blockage and other chemotherapy drugs could be a potential therapeutic strategy in patients with metastasis (m)CRPC.

\section{Targeting the AR-LBD or ARVs}

Enzalutamide and ARN-509 (apalutamide) show a great affinity for AR and are effective in CRPC that is resistant to 
Table 3 Novel potential targets of CRPC therapy

\begin{tabular}{|c|c|c|c|}
\hline Possible targeting pathways & Targeting genes & Potential treatments & References \\
\hline \multicolumn{4}{|l|}{ Androgen axis pathway } \\
\hline Inhibition of androgen synthesis & CYPI7 & VT-464, TAK-700 & 64,65 \\
\hline Targeting HSP protein & HSP90/TCTP & Knockdown & 66 \\
\hline ARVs & ARVs, calpain & $\begin{array}{l}\text { ARN-509, niclosamide, ASC-J9, } \\
\text { CUDC-10I/TAS368I }\end{array}$ & $29,69-73$ \\
\hline AR-NTD & AR-NTD & EPI-00I & 75 \\
\hline Antagonist of $A R$ & AR & $\mathrm{CB}$ & 77 \\
\hline Coactivators of $A R$ & SRC & Dasatinib, saracatinib & 78 \\
\hline Inhibitors of AR expression & $A R$ & ENZ-47I6 & 79 \\
\hline PI3K-AKT pathways & PI3K-AKT & BEZ235, GDC0068 & 80 \\
\hline WNT pathways & PORCN & & 81 \\
\hline Targeting DNA repair & PARP & AZD-228I & 82 \\
\hline Targeting the rearrangement of ETS gene & TMPRSS2-ERG, FLII & DBI 255, PLA2G7, YK-4-279 & 82,84 \\
\hline Chemotherapy & MMP2/9, WNT/ $\beta$-actin & Saikosaponin-d, PEDF & 87,88 \\
\hline \multicolumn{4}{|l|}{ Immunotherapy } \\
\hline \multirow[t]{4}{*}{ Vaccines } & Peptide vaccine & PROSTVAC-VF & 90 \\
\hline & Nucleic acid vaccine & PTVG-HP & 91 \\
\hline & Whole-cell vaccine & GVAX & 82 \\
\hline & Dendritic cell vaccine & Sipulencel-T & 92 \\
\hline \multirow[t]{2}{*}{ Immune checkpoints } & CTLA-4 & Ipilimumab & 94 \\
\hline & PD-I & Nivolumab, pembrotizumab & 95 \\
\hline MDSC & MDSC & Tasquinimod, lenalidomide & 96 \\
\hline PSMA & PSMA & J591 & 97 \\
\hline \multicolumn{4}{|l|}{ Bone metastasis } \\
\hline Chemotherapy & Osteoclast, RANKL & Bisphosphonates, denosumab & 98 \\
\hline \multirow[t]{2}{*}{ Radiotherapy } & DNA of cancer cells & Radium-223 & 99 \\
\hline & ACKI/AR & AIM-I00 & 100 \\
\hline \multicolumn{4}{|l|}{ Other potential drugs } \\
\hline Inhibitors of tyrosine kinase & IGF-IR & Figitumumab, cabozantinib & 101,102 \\
\hline Inhibitors of BET protein & BRD4 & GSK525762, OTX0I5 & 103,104 \\
\hline Inhibitors for $\mathrm{NOTCH}$ pathway & $\mathrm{NOTCH}$ & RO4929097 & 105 \\
\hline Apoptosis and cell cycle pathway & Cell cycle & Escin & 107 \\
\hline
\end{tabular}

Abbreviations: AR, androgen receptor; ARVs, AR splice variants; CRPC, castration-resistant prostate cancer; CTLA-4, cytotoxic T-lymphocyte-associated antigen-4; MDSC, myeloid-derived suppressor cell; NTD, N-terminal domain; PEDF, pigment epithelium-derived factor; PSMA, prostate-specific membrane antigen.

bicalutamide. ${ }^{76}$ Recently, new drugs targeting AR-LBD and ARVs mainly focus on the following types.

Niclosamide, an antiparasitic drug approved by the US Food and Drug Administration was demonstrated to suppress the expression level of AR-V7, but not androgen receptor full length (AR-FL). ${ }^{77}$ It was also reported that niclosamide combined with current antiandrogen agents might possess a satisfactory effect in CRPC patients. Besides, drugs such as ASC-J9 (dimethylcurcumin) and inhibitors of calpain (CUDC-101 and TAS3681) might be useful for CRPC therapy by inhibiting ARVs, according to some studies. ${ }^{78-81}$

\section{Targeting the AR-DBD}

Some researchers believed that the alteration of AR-DBD might be correlated with the production of ARVs, and targeting AR-DBD could be a potential therapeutic strategy for CRPC. ${ }^{82}$

\section{Targeting the AR-NTD}

According to a study, the NTD of AR is responsible for AR transcriptional activity. ${ }^{83}$ As NTD is very important for the activity of all kinds of AR, targeting AR-NTD is expected to be used in CRPC. Several AR-NTD inhibitors (EPI-506, sintokamides) have been under preclinical experiments. ${ }^{82,84}$ As for EPI-506, it is the first agent that could suppress both canonical and variant-related AR signaling, and the ongoing Phase I/II study of EPI-506 (NCT02606123) will evaluate the benefit of EPI-506 in mCRPC patients. According to a study, ${ }^{82}$ EPI-001, the novel depressant of AR-NTD, showed a favorable effect on eliminating the castration resistance which was caused by ARVs.

\section{Antagonist of AR}

In clinic, bicalutamide, flutamide, nilutamide and other antiandrogen drugs are still considered as the first-line treatment for CRPC. However, the curative effects of these drugs are 
not everlasting, and the prostate cancer treated with ADT might advance to CRPC after 6 months. ${ }^{85}$

The core ligand of cyclobutane, which was used as the fourth-generation antiandrogen drug, might be of great importance in CRPC therapy through inhibition of nuclear translocation of AR. ${ }^{86}$

\section{Targeting the coactivators of AR}

According to a clinical trial, depressors of SRC kinase, such as dasatinib and saracatinib, showed a satisfactory effect in CRPC therapy by acting upon AR coactivators. ${ }^{87}$

\section{Inhibiting AR expression}

It might be possible to decrease the AR level by interfering with the expression of AR at the mRNA level. ENZ-4716 is a drug that confirms this hypothesis and is currently in Phase I clinical trial. ${ }^{88}$

\section{Targeting the PI3K-AKT and WNT pathways}

According to previous researches, both PI3K-AKT and WNT pathways play a vital role in the development of CRPC. BEZ235, one of the inhibitors of PI3K-mTOR, and GDC0068, one of the inhibitors of AKT, are both in Phase I clinical trials at present. ${ }^{89}$ Inhibition of WNT signal could potentiate the antitumor activity of the Plk1 inhibitor for CRPC.$^{90}$ Besides, targeting PORCN (porcupine), which is essential for WNT pathway, might be a potential treatment method for CRPC. ${ }^{91}$

\section{Targeting DNA repair}

As mentioned earlier, mutations in DNA repair genes, such as BRCA2, homologous recombination, and nucleotide excision repair and mismatch repair, are common therapy targets in oncotherapy. For instance, inhibitors of poly (ADP-ribose) polymerase, especially olaparib (AZD-2281), showed satisfactory efficacy in CRPC patients according to the clinical trials. ${ }^{82}$

\section{Targeting the rearrangement of ETS gene}

ERG, ETV1, ETV6 and FLI1, which belong to the E twenty-six transcriptional factor family, are considered as the important oncogenes in different cancers. ${ }^{92}$ As one of the most important gene rearrangements in E twenty-six family, the gene rearrangement in TMPRSS2-ERG was deemed to be a potential target in CRPC therapy. Compounds targeting the rearrangement of TMPRSS2-ERG, such as DB1255 and PLA2G7, could regulate the biological function of prostate cells. ${ }^{93,94}$ Besides targeting the classical ERG pathway, YK-4-279 might be useful in inhibiting the proliferation and survival of CRPC cells by suppressing the FLI1 gene..$^{95}$

\section{Chemotherapy for CRPC}

Although the side effects of chemotherapy are inevitable, chemotherapy in CRPC is nonnegligible because it is perfectly capable of killing prostate cancer cells.

Taxanes and epothilones are the typical drugs targeting the microtubules, while docetaxel and cabazitaxel are classical taxane drugs used in CRPC, ${ }^{96}$ and pemetrexed could be used for CRPC under docetaxel-resistant condition. ${ }^{97}$ As a newer trend of CRPC chemotherapy, the effect of applying taxanes in an earlier hormone-naive clinical setting of prostate cancer has been proved by studies. ${ }^{98,99}$ Cabazitaxel, the next generation of taxane drugs, has been shown to be an effective antitumor agent in docetaxel resistance cell lines. ${ }^{100,101}$ In recent years, some reports indicate that the taxanes may have cross-resistance with enzalutamide and abiraterone. As a result, the application of enzalutamide in prostate cancer patients has only a modest effect following docetaxel treatment. ${ }^{102-104}$

Besides the drugs mentioned earlier, several novel chemotherapy drugs have appeared recently. Saikosaponin-d possesses therapeutic potential for CRPC by reversing EMT and inhibiting the expression of MMP2/9 and WNT/ $\beta$ actin. ${ }^{105}$ Moreover, the expression of pigment epitheliumderived factor also could enhance the efficacy of low-dose chemotherapy and improve the prognosis in CRPC. ${ }^{106}$

\section{Immunotherapy in CRPC}

Although immunotherapy in CRPC is still in its initial stage, the prospect of immunotherapy has received more attention in recent decades. Immunotherapy might be of significant importance in both therapy and prevention of CRPC. ${ }^{107}$

\section{Vaccines for prostate cancer}

After the idea of tumor vaccine came up, much effort was put into this field. Up to now, the application of vaccines in prostate cancer has mainly focused on the following:

1. Peptide vaccine: PROSTVAC-VF is a kind of peptide vaccine using PSA as the target antigen and is integrated with avipoxvirus, vaccinia and TRICOM. PROSTVAC-VF could prolong the survival time of the CRPC patients with a satisfactory tolerance according to the clinical trials. ${ }^{108}$ 
2. Nucleic acid vaccine: Nucleic acid vaccine is a kind of vaccine that could express the related target antigen and induce the related immunoreaction. PTVG-HP is a typical nucleic acid vaccine, and its target antigen is prostatic acid phosphatase. According to reports, PTVG-HP could induce the related immunoreaction and has shown a potential usage for CRPC. ${ }^{109}$

3. Whole-cell vaccine (WCV): The WCV could induce multiple kinds of antibodies, but the application of WCV is limited because the immunogenicity of WCV is poor in general. For prostate cancer and CRPC, GVAX, which is modified with costimulators, was effective in Phase I and II clinical trials, but was unsatisfactory in Phase III clinical trial. ${ }^{110}$ Under this condition, the application of WCV in prostate cancer still needs more research.

4. Dendritic cell (DC) vaccine: As the most effective antigen-presenting cell, DC is the first choice for preparation of autogenous cell vaccine. For CRPC, Sipulencel-T is the representative of $\mathrm{DC}$ vaccine and is able to induce CD4 and CD8 contraposing prostate cancer cells. ${ }^{111}$ According to studies, Sipulencel-T could improve the prognosis of the CRPC patients as well.

\section{Immune checkpoints in prostate cancer}

In the immune system, the immune checkpoint is a kind of inhibitory signal pathway, which is important for maintaining self-tolerance and regulating the duration. For prostate cancer, targeting cytotoxic T-lymphocyte-associated antigen-4 and programmed death protein- 1 is the most effective strategy for immune checkpoint-related therapies. ${ }^{112}$ Ipilimumab, which could block or inhibit the cytotoxic T-lymphocyte-associated antigen-4, might prolong the progression-free survival time of CRPC patients, according to clinical trials. ${ }^{113}$ Nivolumab and pembrotizumab represent the immune drugs targeting the programmed death protein-1, but the therapeutic effect of them is not obvious. ${ }^{114}$

Recently, tasquinimod and lenalidomide that target the myeloid-derived suppressor cell showed the antitumor ability by the regulation of immune system and inhibition of angiogenesis in CRPC. ${ }^{115}$

\section{Targeting the prostate-specific membrane antigen} (PSMA)

PSMA, which is upregulated after ADT, has received more attention in recent decades. J591 is a monoclonal antibody of PSMA and might decrease the PSA level and prolong the survival time of CRPC patients. ${ }^{116}$

\section{The therapy of bone metastasis in CRPC}

Bisphosphonates and denosumab, which are the typical drugs for bone metastasis, also show their effectiveness in CRPC by targeting the osteoclasts, while denosumab might inhibit the metastasis of CRPC through RANKL pathway. ${ }^{117}$

Besides chemotherapy, radiotherapy could improve the prognosis of CRPC patients with bone metastasis. Radium-223, a kind of alpha particle radiopharmaceutical, has been proved to be effective in bone metastasis patients and prognosis with low clinical risks. ${ }^{118}$ According to the reports, ACK1/AR pathway could induce the phosphorylation of AR, as well as the upregulation of ataxia-telangiectasia mutated and the regulation of DNA damage, to accelerate the resistance to radiotherapy. AIM-100, an inhibitor of ACK1, could improve the effect of radiotherapy in CRPC. ${ }^{119}$

\section{Other drugs for CRPC} Inhibitors of tyrosine kinase

IGF-1R, a member of tyrosine kinase, could interact with MAPK, PI3K/AKT and other signaling pathways to modulate the development of CRPC. It has been reported that figitumumab, an antibody of IGF-1R, could decrease the expression level of PSA and AR. ${ }^{120}$ Cabozantinib, another oral tyrosine kinase inhibitor, has a significant effect on decreasing the PSA level and suppressing the development of CRPC. ${ }^{121}$

\section{Inhibitors of BET protein}

As mentioned before, BER protein plays a vital role in CRPC through the AR signal pathway. GSK525762, which is the first inhibitor for BRD4 in clinical trial, shows satisfactory therapeutic effects for CRPC patients, while the clinical therapeutic effect of another inhibitor for BRD4, OTX015, still needs to be confirmed by more researches in the future. ${ }^{122,123}$

\section{Inhibitors for NOTCH pathway}

According to the recent research, NOTCH pathway is correlated with the development of CRPC. A novel inhibitor for NOTCH, RO4929097, could suppress the development of CRPC and might be a potential therapeutic target for CRPC. ${ }^{124}$

\section{Apoptosis and cell cycle pathway}

Escin, a natural compound that is extracted from buckeye, has been used for anti-inflammation and detumescence for a long time. ${ }^{125}$ A latest study demonstrated that escin could suppress the proliferation and survival of CRPC cells by regulating cell cycle and inducing apoptosis. ${ }^{126}$ 


\section{Conclusion}

Concomitant with the researches in the mechanism of CRPC and therapy for CRPC, more breakthrough progress has been made. Through comprehensive consideration, the predominant mechanism of CRPC might be the AR signal axis concomitant with other carcinogenesis signals, stress, immunity, tumor microenvironment and so on. With the latest findings in tumor microenvironment, tumor immunity and tumor metabolism, these fields might play indispensable roles in CRPC. However, the interactions between the above mechanisms and the other novel potential mechanisms are still uncertain.

Meanwhile, the clinical guidelines that were established by the European Association of Urology or the American Urological Association are the authoritative references for making therapeutic strategy for CRPC in clinic up to now. With the guidance of clinical guidelines for CRPC, the specific state of each patient, the affordability of the patients and other factors also need to be considered when formulating the therapeutic strategy. Unfortunately, the therapeutic effect is not satisfactory in some CRPC patients nowadays. Therefore, novel and effective therapeutic strategy for CRPC patients is very necessary and exigent in clinic. We hold that the detection of vital gene of CRPC and the application of targeting drugs for CRPC might play an important part in future, while targeting the individual gene expression will bring big rewards for the therapeutic effect and avoid the side effect. Furthermore, the immunotherapy and tumor vaccine of CRPC might be the focus of research in CRPC therapy in future. Although there are still numerous unsolved difficulties in the research upon the mechanism and therapy of CRPC, we believe that great progress would be made with the efforts of researchers all over the world in the future.

\section{Acknowledgments}

This study was supported by the National Natural Science Foundation of China (Grant No 81272560, 81672524 and 81672528) and the Program for New Century Excellent Talents in University from the Department of Education of China (NCET-08-0223).

\section{Author contributions}

$\mathrm{KC}$ contributed to designing this study. KSW and HLR contributed to the collection and analysis of data, discussion, and writing of the manuscript. TBX, DL, HMY and XPZ contributed to the correction of grammatical errors in this article. All authors contributed toward data analysis, drafting and revising the paper and agree to be accountable for all aspects of the work.

\section{Disclosure}

The authors report no conflicts of interest in this work.

\section{References}

1. Mathas S, Misteli T. The dangers of transcription. Cell. 2009;139(6): 1047-1049.

2. Chen W, Zheng R, Baade PD, et al. Cancer statistics in China, 2015. CA Cancer J Clin. 2016;66(2):115-132.

3. Petrylak DP. Practical guide to the use of chemotherapy in castration resistant prostate cancer. Can J Urol. 2014;21(2 Supp 1):77-83.

4. Montgomery RB, Mostaghel EA, Vessella R, et al. Maintenance of intratumoral androgens in metastatic prostate cancer: a mechanism for castrationresistant tumor growth. Cancer Res. 2008;68(11):4447-4454.

5. Fizazi K, Scher HI, Molina A, et al; COU-AA-301 Investigators. Abiraterone acetate for treatment of metastatic castration-resistant prostate cancer: final overall survival analysis of the COU-AA-301 randomised, double-blind, placebo-controlled phase 3 study. Lancet Oncol. 2012;13(10):983-992.

6. Labrie F, Luu-The V, Belanger A, et al. Is dehydroepiandrosterone a hormone? J Endocrinol. 2005;187(2):169-196.

7. Lubik AA, Gunter JH, Hollier BG, et al. IGF2 increases de novo steroidogenesis in prostate cancer cells. Endocr Relat Cancer. 2013;20(2): 173-186.

8. Hofland J, van Weerden WM, Steenbergen J, Dits NF, Jenster G, de Jong FH. Activin A stimulates AKR1C3 expression and growth in human prostate cancer. Endocrinology. 2012;153(12):5726-5734.

9. Chun JY, Nadiminty N, Dutt S, et al. Interleukin-6 regulates androgen synthesis in prostate cancer cells. Clin Cancer Res. 2009;15(15): 4815-4822.

10. Lubik AA, Gunter JH, Hollier BG, et al. IGF2 increases de novo steroidogenesis in prostate cancer cells. Endocr Relat Cancer. 2013; 20(2):173-186.

11. Locke JA, Guns ES, Lehman ML, et al. Arachidonic acid activation of intratumoral steroid synthesis during prostate cancer progression to castration resistance. Prostate. 2010;70(3):239-251.

12. Stanbrough M, Bubley GJ, Ross K, et al. Increased expression of genes converting adrenal androgens to testosterone in androgen-independent prostate cancer. Cancer Res. 2006;66(5):2815-2825.

13. Mizokami A, Koh E, Izumi K, et al. Prostate cancer stromal cells and $\mathrm{LNCaP}$ cells coordinately activate the androgen receptor through synthesis of testosterone and dihydrotestosterone from dehydroepiandrosterone. Endocr Relat Cancer. 2009;16(4):1139-1155.

14. Kelly WK, Halabi S, Carducci M, et al. Randomized, double-blind, placebo-controlled phase III trial comparing docetaxel and prednisone with or without bevacizumab in men with metastatic castration-resistant prostate cancer: CALGB 90401. J Clin Oncol. 2012;30(13):1534-1540.

15. Mathas S, Misteli T. The dangers of transcription. Cell. 2009;139(6): 1047-1049.

16. Linja MJ, Savinainen KJ, Saramaki OR, Tammela TL, Vessella RL, Visakorpi T. Amplification and overexpression of androgen receptor gene in hormone-refractory prostate cancer. Cancer Res. 2001; 61(9):3550-3555

17. Haapala K, Kuukasjarvi T, Hyytinen E, Rantala I, Helin HJ, Koivisto PA. Androgen receptor amplification is associated with increased cell proliferation in prostate cancer. Hum Pathol. 2007;38(3):474-478.

18. Lee JH, Kang M, Wang $\mathrm{H}$, et al. Endostatin inhibits androgenindependent prostate cancer growth by suppressing nuclear receptormediated oxidative stress. FASEB J. 2017;31(4):1608-1619. 
19. Arora VK, Schenkein E, Murali R, et al. Glucocorticoid receptor confers resistance to antiandrogens by bypassing androgen receptor blockade. Cell. 2013;155(6):1309-1322.

20. Shiota M, Takeuchi A, Song Y, et al. Y-box binding protein-1 promotes castration-resistant prostate cancer growth via androgen receptor expression. Endocr Relat Cancer. 2011;18(4):505-517.

21. Yang M, Wang J, Wang L, et al. Estrogen induces androgen-repressed SOX4 expression to promote progression of prostate cancer cells. Prostate. 2015;75(13):1363-1375.

22. De Miguel F, Lee SO, Onate SA, Gao AC. Stat 3 enhances transactivation of steroid hormone receptors. Nucl Recept. 2003;1(1):3.

23. Jin RJ, Lho Y, Connelly L, et al. The nuclear factor-kappaB pathway controls the progression of prostate cancer to androgen-independent growth. Cancer Res. 2008;68(16):6762-6769.

24. Nadiminty N, Lou W, Sun M, et al. Aberrant activation of the androgen receptor by NF-kappaB2/p52 in prostate cancer cells. Cancer Res. 2010; 70(8):3309-3319.

25. Balbas MD, Evans MJ, Hosfield DJ, et al. Overcoming mutationbased resistance to antiandrogens with rational drug design. Elife. 2013;2:e00499.

26. Dehm SM, Tindall DJ. Alternatively spliced androgen receptor variants. Endocr Relat Cancer. 2011;18(5):R183-R196.

27. Joshi JB, Patel D, Morton DJ, et al. Inactivation of ID4 promotes a CRPC phenotype with constitutive AR activation through FKBP52. Mol Oncol. 2017;11(4):337-357.

28. Karacosta LG, Kuroski LA, Hofmann WA, et al. Nucleoporin 62 and $\mathrm{Ca}(2+)$ /calmodulin dependent kinase kinase 2 regulate androgen receptor activity in castrate resistant prostate cancer cells. Prostate. 2016;76(3):294-306.

29. Azad AA, Eigl BJ, Murray RN, Kollmannsberger C, Chi KN. Efficacy of enzalutamide following abiraterone acetate in chemotherapy-naive metastatic castration-resistant prostate cancer patients. Eur Urol. 2015; 67(1):23-29.

30. Zhou HJ, Yan J, Luo W, et al. SRC-3 is required for prostate cancer cell proliferation and survival. Cancer Res. 2005;65(17):7976-7983.

31. Jozwik KM, Carroll JS. Pioneer factors in hormone-dependent cancers. Nat Rev Cancer. 2012;12(6):381-385.

32. Wang T, Song W, Chen Y, et al. Flightless I homolog represses prostate cancer progression through targeting androgen receptor signaling. Clin Cancer Res. 2016;22(6):1531-1544.

33. Wang S, Gao J, Lei Q, et al. Prostate-specific deletion of the murine Pten tumor suppressor gene leads to metastatic prostate cancer. Cancer Cell. 2003;4(3):209-221.

34. Gelman IH. Androgen receptor activation in castration-recurrent prostate cancer: the role of Src-family and Ack1 tyrosine kinases. Int J Biol Sci. 2014;10(6):620-626.

35. Mateo J, Boysen G, Barbieri CE, et al. DNA repair in prostate cancer: biology and clinical implications. Eur Urol. 2017;71(3):417-425.

36. Schiewer MJ, Goodwin JF, Han S, et al. Dual roles of PARP-1 promote cancer growth and progression. Cancer Discov. 2012;2(12):1134-1149.

37. Kote-Jarai Z, Leongamornlert D, Saunders E, et al. BRCA2 is a moderate penetrance gene contributing to young-onset prostate cancer: implications for genetic testing in prostate cancer patients. Br J Cancer. 2011;105(8):1230-1234.

38. Kokontis JM, Lin HP, Jiang SS, et al. Androgen suppresses the proliferation of androgen receptor-positive castration-resistant prostate cancer cells via inhibition of Cdk2, CyclinA, and Skp2. PLoS One. 2014;9(10):e109170.

39. Levesque E, Huang SP, Audet-Walsh E, et al. Molecular markers in key steroidogenic pathways, circulating steroid levels, and prostate cancer progression. Clin Cancer Res. 2013;19(3):699-709.

40. Mitsiades N, Sung CC, Schultz N, et al. Distinct patterns of dysregulated expression of enzymes involved in androgen synthesis and metabolism in metastatic prostate cancer tumors. Cancer Res. 2012;72(23): 6142-6152.

41. Shiota M, Bishop JL, Nip KM, et al. Hsp27 regulates epithelial mesenchymal transition, metastasis, and circulating tumor cells in prostate cancer. Cancer Res. 2013;73(10):3109-3119.
42. Izumi K, Fang LY, Mizokami A, et al. Targeting the androgen receptor with siRNA promotes prostate cancer metastasis through enhanced macrophage recruitment via CCL2/CCR2-induced STAT3 activation. Embo Mol Med. 2013;5(9):1383-1401.

43. Karkera J, Steiner H, Li W, et al. The anti-interleukin-6 antibody siltuximab down-regulates genes implicated in tumorigenesis in prostate cancer patients from a phase I study. Prostate. 2011;71(13): $1455-1465$.

44. Lee SO, Lou W, Nadiminty N, Lin X, Gao AC. Requirement for NF-(kappa)B in interleukin-4-induced androgen receptor activation in prostate cancer cells. Prostate. 2005;64(2):160-167.

45. Waugh DJ, Wilson C. The interleukin-8 pathway in cancer. Clin Cancer Res. 2008;14(21):6735-6741.

46. Taichman RS, Cooper C, Keller ET, Pienta KJ, Taichman NS, McCauley LK. Use of the stromal cell-derived factor-1/CXCR4 pathway in prostate cancer metastasis to bone. Cancer Res. 2002;62(6): 1832-1837.

47. Shen H, Schuster R, Lu B, Waltz SE, Lentsch AB. Critical and opposing roles of the chemokine receptors CXCR2 and CXCR3 in prostate tumor growth. Prostate. 2006;66(16):1721-1728.

48. Wang J, Lu Y, Wang J, Koch AE, Zhang J, Taichman RS. CXCR6 induces prostate cancer progression by the AKT/mammalian target of rapamycin signaling pathway. Cancer Res. 2008;68(24):10367-10376.

49. Singh RK, Lokeshwar BL. The IL-8-regulated chemokine receptor CXCR7 stimulates EGFR signaling to promote prostate cancer growth. Cancer Res. 2011;71(9):3268-3277.

50. Wang J, Shiozawa Y, Wang J, et al. The role of CXCR7/RDC1 as a chemokine receptor for CXCL12/SDF-1 in prostate cancer. $J$ Biol Chem. 2008;283(7):4283-4294

51. Pasquinelli AE. MicroRNAs and their targets: recognition, regulation and an emerging reciprocal relationship. Nat Rev Genet. 2012;13(4): 271-282.

52. Singh A, Happel C, Manna SK, et al. Transcription factor NRF2 regulates miR-1 and miR-206 to drive tumorigenesis. J Clin Invest. 2013; 123(7):2921-2934.

53. Hiroki E, Akahira J, Suzuki F, et al. Changes in microRNA expression levels correlate with clinicopathological features and prognoses in endometrial serous adenocarcinomas. Cancer Sci. 2010;101(1):241-249.

54. Jalava SE, Urbanucci A, Latonen L, et al. Androgen-regulated miR-32 targets BTG2 and is overexpressed in castration-resistant prostate cancer. Oncogene. 2012;31(41):4460-4471.

55. Yang L, Lin C, Jin C, et al. IncRNA-dependent mechanisms of androgen-receptor-regulated gene activation programs. Nature. 2013; 500(7464):598-602.

56. Yang F, Zhang H, Mei Y, Wu M. Reciprocal regulation of HIF-1alpha and lincRNA-p21 modulates the Warburg effect. Mol Cell. 2014; 53(1):88-100.

57. Scaravilli M, Porkka KP, Brofeldt A, et al. MiR-1247-5p is overexpressed in castration resistant prostate cancer and targets MYCBP2. Prostate. 2015;75(8):798-805.

58. Prensner JR, Iyer MK, Balbin OA, et al. Transcriptome sequencing across a prostate cancer cohort identifies PCAT-1, an unannotated lincRNA implicated in disease progression. Nat Biotechnol. 2011; 29(8):742-749.

59. Yap KL, Li S, Munoz-Cabello AM, et al. Molecular interplay of the noncoding RNA ANRIL and methylated histone H3 lysine 27 by polycomb CBX7 in transcriptional silencing of INK4a. Mol Cell. 2010; 38(5):662-674.

60. Beltran H, Rickman DS, Park K, et al. Molecular characterization of neuroendocrine prostate cancer and identification of new drug targets. Cancer Discov. 2011;1(6):487-495.

61. Arsov C, Winter C, Rabenalt R, Albers P. Current second-line treatment options for patients with castration resistant prostate cancer (CRPC) resistant to docetaxel. Urol Oncol. 2012;30(6):762-771.

62. Ryan CJ, Saylor PJ, Everly JJ, Sartor O. Bone-targeting radiopharmaceuticals for the treatment of bone-metastatic castration-resistant prostate cancer: exploring the implications of new data. Oncologist. 2014;19(10):1012-1018. 
63. Massari F, Maines F, Modena A, et al. Castration resistant prostate cancer (CRPC): state of the art, perspectives and new challenges. Anticancer Agents Med Chem. 2013;13(6):872-886.

64. Suarez C, Morales-Barrera R, Ramos V, et al. Role of immunotherapy in castration-resistant prostate cancer (CRPC). BJU Int. 2014;113(3): 367-375.

65. Dar JA, Eisermann K, Masoodi KZ, et al. N-terminal domain of the androgen receptor contains a region that can promote cytoplasmic localization. J Steroid Biochem Mol Biol. 2014;139:16-24.

66. Narayanan S, Srinivas S, Feldman D. Androgen-glucocorticoid interactions in the era of novel prostate cancer therapy. Nat Rev Urol. 2016; 13(1):47-60.

67. Ye D, Huang Y, Zhou F, et al. A phase 3, double-blind, randomized placebo-controlled efficacy and safety study of abiraterone acetate in chemotherapy-naïve patients with $\mathrm{MCRPC}$ in China, Malaysia, Thailand and Russia. Asian J Urol. 2017;4(2):75-85.

68. Toren PJ, Kim S, Pham S, et al. Anticancer activity of a novel selective CYP17A1 inhibitor in preclinical models of castrate-resistant prostate cancer. Mol Cancer Ther. 2015;14(1):59-69.

69. Fizazi K, Jones R, Oudard S, et al. Phase III, randomized, double-blind, multicenter trial comparing orteronel (TAK-700) plus prednisone with placebo plus prednisone in patients with metastatic castration-resistant prostate cancer that has progressed during or after docetaxel-based therapy: ELM-PC 5. J Clin Oncol. 2015;33(7):723-731.

70. Solit DB, Scher HI, Rosen N. Hsp90 as a therapeutic target in prostate cancer. Semin Oncol. 2003;30(5):709-716.

71. Baylot V, Katsogiannou M, Andrieu C, et al. Targeting TCTP as a new therapeutic strategy in castration-resistant prostate cancer. Mol Ther. 2012;20(12):2244-2256.

72. O’Malley KJ, Langmann G, Ai J, Ramos-Garcia R, Vessella RL, Wang Z. Hsp90 inhibitor 17-AAG inhibits progression of LuCaP35 xenograft prostate tumors to castration resistance. Prostate. 2012;72(10):1117-1123.

73. He S, Zhang C, Shafi AA, et al. Potent activity of the Hsp90 inhibitor ganetespib in prostate cancer cells irrespective of androgen receptor status or variant receptor expression. Int J Oncol. 2013;42(1):35-43.

74. Zoubeidi A, Zardan A, Beraldi E, et al. Cooperative interactions between androgen receptor (AR) and heat-shock protein 27 facilitate AR transcriptional activity. Cancer Res. 2007;67(21):10455-10465.

75. Ischia J, Saad F, Gleave M. The promise of heat shock protein inhibitors in the treatment of castration resistant prostate cancer. Curr Opin Urol. 2013;23(3):194-200.

76. Tran C, Ouk S, Clegg NJ, et al. Development of a second-generation antiandrogen for treatment of advanced prostate cancer. Science. 2009;324(5928):787-790.

77. Liu C, Lou W, Zhu Y, et al. Niclosamide inhibits androgen receptor variants expression and overcomes enzalutamide resistance in castrationresistant prostate cancer. Clin Cancer Res. 2014;20(12):3198-3210.

78. Yamashita S, Lai KP, Chuang KL, et al. ASC-J9 suppresses castrationresistant prostate cancer growth through degradation of full-length and splice variant androgen receptors. Neoplasia. 2012;14(1):74-83.

79. Libertini SJ, Tepper CG, Rodriguez V, Asmuth DM, Kung HJ, Mudryj M. Evidence for calpain-mediated androgen receptor cleavage as a mechanism for androgen independence. Cancer Res. 2007;67(19): 9001-9005.

80. Sun H, Mediwala SN, Szafran AT, Mancini MA, Marcelli M. CUDC101, a novel inhibitor of full-length Androgen Receptor (flAR) and Androgen Receptor Variant 7 (AR-V7) Activity: mechanism of action and in vivo efficacy. Horm Cancer. 2016;7(3):196-210.

81. Teply BA, Antonarakis ES. Novel mechanism-based therapeutics for androgen axis blockade in castration-resistant prostate cancer. Curr Opin Endocrinol Diabetes Obes. 2016;23(3):279-290.

82. Andersen RJ, Mawji NR, Wang J, et al. Regression of castraterecurrent prostate cancer by a small-molecule inhibitor of the aminoterminus domain of the androgen receptor. Cancer Cell. 2010;17(6): $535-546$

83. Banuelos CA, Lal A, Tien AH, et al. Characterization of niphatenones that inhibit androgen receptor N-terminal domain. PLoS One. 2014;9(9):e107991.
84. Sadar MD, Williams DE, Mawji NR, et al. Sintokamides A to E, chlorinated peptides from the sponge Dysidea sp. that inhibit transactivation of the N-terminus of the androgen receptor in prostate cancer cells. Org Lett. 2008;10(21):4947-4950.

85. Michels J. Enzalutamide versus bicalutamide in castration-resistant prostate cancer: the STRIVE trial-there is no significant reduction in death (Yet). J Clin Oncol. 2017;35(1):123.

86. Pollock JA, Wardell SE, Parent AA, et al. Inhibiting androgen receptor nuclear entry in castration-resistant prostate cancer. Nat Chem Biol. 2016;12(10):795-801.

87. Yu EY, Wilding G, Posadas E, et al. Phase II study of dasatinib in patients with metastatic castration-resistant prostate cancer. Clin Cancer Res. 2009;15(23):7421-7428.

88. Bianchini D, Omlin A, Pezaro C, et al. First-in-human Phase I study of EZN-4176, a locked nucleic acid antisense oligonucleotide to exon 4 of the androgen receptor mRNA in patients with castration-resistant prostate cancer. Br J Cancer. 2013;109(10):2579-2586.

89. Carver BS, Chapinski C, Wongvipat J, et al. Reciprocal feedback regulation of PI3K and androgen receptor signaling in PTEN-deficient prostate cancer. Cancer Cell. 2011;19(5):575-586.

90. Li J, Karki A, Hodges KB, et al. Cotargeting polo-like kinase 1 and the Wnt/beta-catenin signaling pathway in castration-resistant prostate cancer. Mol Cell Biol. 2015;35(24):4185-4198.

91. Zhang LS, Lum L. Delivery of the porcupine inhibitor WNT974 in mice. Methods Mol Biol. 2016;1481:111-117.

92. Hollenhorst PC, McIntosh LP, Graves BJ. Genomic and biochemical insights into the specificity of ETS transcription factors. Annu Rev Biochem. 2011;80:437-471.

93. Nhili R, Peixoto P, Depauw S, et al. Targeting the DNA-binding activity of the human ERG transcription factor using new heterocyclic dithiophene diamidines. Nucleic Acids Res. 2013;41(1):125-138.

94. Vainio P, Gupta S, Ketola K, et al. Arachidonic acid pathway members PLA2G7, HPGD, EPHX2, and CYP4F8 identified as putative novel therapeutic targets in prostate cancer. Am J Pathol. 2011;178(2):525-536.

95. Rahim S, Beauchamp EM, Kong Y, Brown ML, Toretsky JA, Uren A. YK-4-279 inhibits ERG and ETV1 mediated prostate cancer cell invasion. PLos One. 2011;6(4):e19343.

96. Kim SJ, Kim SI. Current treatment strategies for castration-resistant prostate cancer. Korean J Urol. 2011;52(3):157-165.

97. Caffo O, Fratino L, Barbieri R, et al. Pemetrexed as second-line chemotherapy for castration-resistant prostate cancer after docetaxel failure: results from a phase II study. Urol Oncol. 2013;31(2):180-186.

98. Shiota M, Yokomizo A, Eto M. Taxane chemotherapy for hormonenaive prostate cancer with its expanding role as breakthrough strategy. Front Oncol. 2015;5:304.

99. Botrel TE, Clark O, Lima Pompeo AC, et al. Efficacy and safety of combined Androgen Deprivation Therapy (ADT) and docetaxel compared with ADT alone for metastatic hormone-naive prostate cancer: a systematic review and meta-analysis. PLoS One. 2016;11(6):e0157660.

100. Mita AC, Denis LJ, Rowinsky EK, et al. Phase I and pharmacokinetic study of XRP6258 (RPR 116258A), a novel taxane, administered as a 1 -hour infusion every 3 weeks in patients with advanced solid tumors. Clin Cancer Res. 2009;15(2):723-730.

101. Yap TA, Pezaro CJ, de Bono JS. Cabazitaxel in metastatic castrationresistant prostate cancer. Expert Rev Anticancer Ther. 2012;12(9) 1129-1136.

102. Darshan MS, Loftus MS, Thadani-Mulero M, et al. Taxane-induced blockade to nuclear accumulation of the androgen receptor predicts clinical responses in metastatic prostate cancer. Cancer Res. 2011; 71(18):6019-6029.

103. Badrising S, van der Noort V, van Oort IM, et al. Clinical activity and tolerability of enzalutamide (MDV3100) in patients with metastatic, castration-resistant prostate cancer who progress after docetaxel and abiraterone treatment. Cancer. 2014;120(7):968-975.

104. Bianchini D, Lorente D, Rodriguez-Vida A, et al. Antitumour activity of enzalutamide (MDV3100) in patients with metastatic castrationresistant prostate cancer (CRPC) pre-treated with docetaxel and abiraterone. Eur J Cancer. 2014;50(1):78-84. 
105. Zhong D, Zhang HJ, Jiang YD, et al. Saikosaponin-d: a potential chemotherapeutics in castration resistant prostate cancer by suppressing cancer metastases and cancer stem cell phenotypes. Biochem Biophys Res Commun. 2016;474(4):722-729.

106. Nelius T, Martinez-Marin D, Hirsch J, et al. Pigment epitheliumderived factor expression prolongs survival and enhances the cytotoxicity of low-dose chemotherapy in castration-refractory prostate cancer. Cell Death Dis. 2014;5:e1210.

107. Gulley JL, Madan RA. Developing immunotherapy strategies in the treatment of prostate cancer. Asian J Urol. 2016;3(4):278-285.

108. Kantoff PW, Schuetz TJ, Blumenstein BA, et al. Overall survival analysis of a phase II randomized controlled trial of a Poxviral-based PSA-targeted immunotherapy in metastatic castration-resistant prostate cancer. J Clin Oncol. 2010;28(7):1099-1105.

109. Becker JT, Olson BM, Johnson LE, Davies JG, Dunphy EJ, McNeel DG. DNA vaccine encoding prostatic acid phosphatase (PAP) elicits long-term T-cell responses in patients with recurrent prostate cancer. J Immunother. 2010;33(6):639-647.

110. Karan D, Van Veldhuizen P. Combination immunotherapy with prostate GVAX and ipilimumab: safety and toxicity. Immunotherapy. 2012;4(6):577-580.

111. Shore ND, Mantz CA, Dosoretz DE, et al. Building on sipuleucel-T for immunologic treatment of castration-resistant prostate cancer. Cancer Control. 2013;20(1):7-16.

112. Antonarakis ES. Combining active immunotherapy with immune checkpoint blockade for the treatment of advanced prostate cancer. Asian J Androl. 2012;14(4):520-521.

113. Kwon ED, Drake CG, Scher HI, et al; CA184-043 Investigators. Ipilimumab versus placebo after radiotherapy in patients with metastatic castration-resistant prostate cancer that had progressed after docetaxel chemotherapy (CA184-043): a multicentre, randomised, double-blind, phase 3 trial. Lancet Oncol. 2014;15(7):700-712.

114. Sanlorenzo M, Vujic I, Daud A, et al. Pembrolizumab cutaneous adverse events and their association with disease progression. JAMA Dermatol. 2015;151(11):1206-1212.

115. Madan RA, Karzai FH, Ning YM, et al. Phase II trial of docetaxel, bevacizumab, lenalidomide and prednisone in patients with metastatic castration-resistant prostate cancer. BJU Int. 2016;118(4): 590-597.
116. Madan RA, Karzai FH, Ning YM, et al. Phase II trial of docetaxel, bevacizumab, lenalidomide and prednisone in patients with metastatic castration-resistant prostate cancer. BJU Int. 2016;118(4):590-597.

117. Chu GC, Zhau HE, Wang R, et al. RANK- and c-Met-mediated signal network promotes prostate cancer metastatic colonization. Endocr Relat Cancer. 2014;21(2):311-326.

118. Ryan CJ, Saylor PJ, Everly JJ, Sartor O. Bone-targeting radiopharmaceuticals for the treatment of bone-metastatic castration-resistant prostate cancer: exploring the implications of new data. Oncologist. 2014;19(10):1012-1018.

119. Mahajan K, Coppola D, Rawal B, et al. Ack1-mediated androgen receptor phosphorylation modulates radiation resistance in castrationresistant prostate cancer. J Biol Chem. 2012;287(26):22112-22122.

120. Chi KN, Gleave ME, Fazli L, et al. A phase II pharmacodynamic study of preoperative figitumumab in patients with localized prostate cancer. Clin Cancer Res. 2012;18(12):3407-3413.

121. Smith DC, Smith MR, Sweeney C, et al. Cabozantinib in patients with advanced prostate cancer: results of a phase II randomized discontinuation trial. J Clin Oncol. 2013;31(4):412-419.

122. Wyce A, Degenhardt Y, Bai Y, et al. Inhibition of BET bromodomain proteins as a therapeutic approach in prostate cancer. Oncotarget. 2013;4(12):2419-2429.

123. Coude MM, Braun T, Berrou J, et al. BET inhibitor OTX015 targets BRD2 and BRD4 and decreases c-MYC in acute leukemia cells. Oncotarget. 2015;6(19):17698-17712.

124. Wyce A, Degenhardt Y, Bai Y, et al. Inhibition of BET bromodomain proteins as a therapeutic approach in prostate cancer. Oncotarget. 2013;4(12):2419-2429.

125. Sirtori CR. Aescin: pharmacology, pharmacokinetics and therapeutic profile. Pharmacol Res. 2001;44(3):183-193.

126. Piao S, Kang M, Lee YJ, et al. Cytotoxic effects of escin on human castration-resistant prostate cancer cells through the induction of apoptosis and G2/M cell cycle arrest. Urology. 2014;84(4): 982.e1-982.e7.
OncoTargets and Therapy

\section{Publish your work in this journal}

OncoTargets and Therapy is an international, peer-reviewed, open access journal focusing on the pathological basis of all cancers, potential targets for therapy and treatment protocols employed to improve the management of cancer patients. The journal also focuses on the impact of management programs and new therapeutic agents and protocols on

\section{Dovepress}

patient perspectives such as quality of life, adherence and satisfaction The manuscript management system is completely online and includes a very quick and fair peer-review system, which is all easy to use. Visit http://www.dovepress.com/testimonials.php to read real quotes from published authors. 